\title{
O Garrano como fator de sustentabilidade de territórios de rede natura 2000
}

\author{
Garrano as a sustainability factor of territories from natural network 2000 \\ Ana Alexandra Marta-Costaํ (D), Rui Pinto ${ }^{1}$ (D), Filipa Torres-Manso ${ }^{1}$ (1) \\ ${ }^{1}$ Universidade de Trás-os-Montes e Alto Douro (UTAD) e Centro de Estudos Transdisciplinares para o Desenvolvimento \\ (CETRAD), Vila Real, Portugal. E-mails: amarta@utad.pt, ruipinto@utad.pt, ftorres@utad.pt
}

Como citar: Marta-Costa, A. A., Pinto, R. \& Torres-Manso, F. (2021). O Garrano como fator de sustentabilidade de territórios de rede natura 2000. Revista de Economia e Sociologia Rural, 59(1), e238887. https://doi.org/10.1590/1806-9479.2021.238887.

\begin{abstract}
Resumo: A evolução da população rural e de animais de algumas raças autóctones portuguesas tem demonstrado níveis de regressão preocupantes, com consequências ambientais e ecológicas, na gestão e no ordenamento do território e na sua sustentabilidade, nomeadamente, no que se refere à dimensão socioeconómica e à própria coesão territorial. Neste trabalho, tendo por base entrevistas realizadas a criadores, empresas e associações que se dedicam à criação e proteção da raça de equídeos Garrana, usada para diversos fins, pretende-se identificar os benefícios da adoção de um sistema de exploração que inclua o Garrano destacando, também, as suas principais debilidades. A abordagem será desenvolvida atendendo às dimensões ambiental, económica e social da sustentabilidade. Os resultados evidenciam a importância destes animais, não apenas enquanto património genético vivo, mas também ao nível da defesa da floresta contra incêndios, concretamente, no controlo de biomassa combustível. No entanto, será necessária a definição de uma estratégia concertada que permita valorizar o seu contributo na economia das explorações ou empresas, o que deverá refletir-se no acréscimo do bemestar da população, na estabilização do efetivo animal e na sustentabilidade do território.
\end{abstract}

Palavras-chave: Garrano, biomassa, valorização, sustentabilidade.

\begin{abstract}
The evolution of the rural population and livestock of some Portuguese native breeds has shown worrying levels of regression, with environmental and ecological consequences, in the management and planning of the territory and its sustainability, namely regarding the socio-economic dimension and territorial cohesion itself. Based on interviews with breeders, companies, and associations dedicated to the breeding and protection of the Garrano horse breed, used for various purposes, this paper aims to identify the benefits of adopting a production system that includes Garrano, highlighting also its main weaknesses. The approach will be developed taking into account the environmental, economic, and social dimensions of sustainability. The results show the important role of these animals, not only as a living genetic heritage but also in terms of the protection of forests against fires, regarding the control of fuel biomass. However, a concerted strategy will need to be devised to enhance its contribution to the economy of farms or enterprises. This should be reflected in the increase of the welfare of the population, the stabilization of the animal herd, and the sustainability of the territory.
\end{abstract}

Keywords: Garrano, biomass, valorization, sustainability.

\section{INTRODUÇÃO}

O território português apresenta assimetrias de ordem diversa que resultam não apenas de elementos geográficos e socioculturais diferenciados, mas também da aplicação de políticas e estratégias de desenvolvimento, definidas e implementadas ao longo de várias décadas (Soukiazis \& Antunes, 2004; Portugal, 2006; Silva, 2012; Viegas \& Antunes, 2012). Esta realidade reflete profundas desigualdades no desenvolvimento, nomeadamente, entre 0 
litoral e o interior, com consequências negativas para a economia das regiões de baixa densidade populacional. Algumas das principais consequências resultam de fenómenos migratórios que, em virtude da procura, por parte das populações enquadradas numa faixa etária mais jovem, de emprego e melhores condições de vida, contribuem, cada vez mais, para o despovoamento de alguns territórios, desequilíbrios demográficos, envelhecimento populacional e para uma transformação da paisagem, nomeadamente no que se refere ao abandono de terrenos outrora ocupados por culturas e/ou pastoreados por animais. A ausência de gestão e uso dos espaços agroflorestais teve como resultado imediato a redução da atividade agropecuária e a acumulação de biomassa altamente combustível, densa e concentrada em áreas contíguas, aumentando o risco dos incêndios rurais, ao mesmo tempo que atenta contra a biodiversidade e sustentabilidade de ecossistemas diversificados (Reis et al., 2014).

A consciência da complexidade e da interação entre as dimensões ambiental, económica, e social dos sistemas agroflorestais tem fundamentado o debate em torno da ideia de sustentabilidade que reclama uma política de ambiente economicamente eficiente, um crescimento económico que apoie o progresso social e respeite o ambiente, e uma política social que favoreça o desempenho económico (Altieri, 1994; Comissão das Comunidades Europeias, 2001; Marta-Costa et al., 2012; Silva \& Marta-Costa, 2013).

Do ponto de vista ambiental, um modelo agroflorestal que vise a sustentabilidade inclui a redução do uso de recursos não renováveis e um uso racional de recursos renováveis, encorajando a produção local de alimentos adaptados ao ambiente natural e socioeconómico (Esquivel, 1998; Marta-Costa et al., 2012; Silva \& Marta-Costa, 2013). A viabilidade económica pode ser alcançada através do uso mais eficiente dos fatores de produção, passando pela adoção de espécies adaptadas ao ambiente local, ou seja, a construção de sistemas mais integrados e mais estáveis face às pressões externas (Esquivel, 1998; Silva \& Marta-Costa, 2013). Já os aspetos sociais de uma atividade agroflorestal sustentável estão principalmente relacionados com uma distribuição equitativa de receitas, de acesso aos recursos e à informação, e duma participação ativa dos envolvidos na investigação e processos de tomada de decisão. Deve ser o reflexo dos valores sociais, ser consonante com as instituições e culturas tradicionais, e deve ser capaz de gerar elevados níveis de autonomia (Esquivel, 1998; Silva \& Marta-Costa, 2013).

Neste sentido, a sustentabilidade parece ser a chave para o futuro do setor agroflorestal assente em modelos produtivos, estáveis, resilientes, adaptáveis, equitativos e autónomos, que beneficiem também a envolvente mais e menos direta, dada a ausência cada vez menor de limites (Marta-Costa, 2010a).

Aos sistemas de exploração de raças autóctones têm sido reconhecidos muitos destes atributos de sustentabilidade (Marta-Costa, 2010b). A pastorícia é apontada, nomeadamente no Plano Nacional de Defesa da Floresta Contra Incêndios, em vários Planos Regionais de Ordenamento Florestal e em outros Planos Setoriais de Ordenamento do Território, como uma atividade muito eficaz na gestão da biomassa combustível acumulada em diversos territórios, especificamente da Rede Natura 2000, reduzindo o risco de incêndio. Paradigma português desta realidade e do reconhecimento da aptidão de alguns espaços para o pastoreio de animais, é o programa de apoio financiado pelo Fundo Florestal Permanente para o eixo relativo à defesa da floresta contra incêndios na vertente gestão de combustíveis, que, entre outras iniciativas, apoia aquela que se tornou mais mediática, embora discutível, pelo cognome atribuído de "cabras sapadoras". As mais-valias económicas são também percetíveis diretamente pela venda das crias obtidas e indiretamente pela redução dos custos de produção (caso dos bovinos autóctones, Marta-Costa, 2010b; Sousa \& Marta-Costa, 2016), além de complementadas com ajudas monetárias promovidas por medidas de política europeia (caso das medidas agroambientais, Portugal, 2015).

Outras iniciativas têm sido direcionadas para a valorização dos produtos obtidos, com a certificação da sua qualidade através da Denominação de Origem Protegida (DOP), Indicação Geográfica Protegida (IGP) ou produtos obtidos pelo modo de produção biológico (Parlamento Europeu e do Conselho, 2018).

Neste trabalho, toma particular destaque o Garrano, raça de equídeos autóctone lusogalaica em perigo de extinção, existente no território do Norte de Portugal, em concreto em 
zonas de montanha e espaços classificados como pertencentes à Rede Natura 2000. Porém, apesar dos manifestos apoios e da sua importância enquanto património genético e na proteção do ambiente e preservação da paisagem rural, também apresenta dificuldades e constrangimentos relatados pelos diversos agentes envolvidos na sua exploração, evidenciando a necessidade de maior proteção, valorização e promoção da raça. Neste sentido, este trabalho tem por objetivo identificar os benefícios da adoção de um sistema de exploração que inclua o Garrano, contrabalançando, também, as suas principais debilidades. A identificação destes elementos deverá suportar a definição de estratégias de valorização que passem pela integração do Garrano como fator de sustentabilidade nos territórios anteriormente mencionados.

O trabalho está estruturado em quatro secções principais. Para além do seu breve enquadramento inicial, apresenta-se a metodologia utilizada na Secção 2. Na Secção 3 são expostos os resultados obtidos e, na Seç̧ão 4, são evidenciadas as principais conclusões.

\section{METODOLOGIA}

Para o desenvolvimento deste trabalho foi desenvolvido um conjunto de entrevistas a criadores, empresas e associações que se dedicam à criação e/ou valorização e/ou proteção da raça autóctone equina Garrana. Adicionalmente, foram realizadas entrevistas a empresas dedicadas a outras atividades e raças animais, por forma a explorar o respetivo modelo empresarial desenvolvido e a sua potencial adoção pelos exploradores do Garrano.

As entrevistas foram realizadas tendo por base um guia de inquérito organizado nas cinco secções seguintes, tendo sido, na sua maioria, realizadas de forma presencial e com gravação autorizada pelos seus intervenientes:

- Secção I: Caracterização do inquirido e sua organização;

- Secção II: Caracterização do sistema de exploração utilizado;

- Secção III: Aptidão, problemas e potencialidades da raça Garrana;

- Secção IV: Estratégias em curso para a proteção e valorização do Garrano;

- Secção V: Sugestão de novas estratégias para a sustentabilidade da exploração do Garrano, gestão do território, e para o desenvolvimento local.

Para além das entrevistas, a informação foi complementada com pesquisa bibliográfica prévia e posteriormente, por forma à melhor identificação das questões para análise e para a exploração dos resultados obtidos, respetivamente.

\section{RESULTADOS}

\subsection{Breve caracterização do sistema de exploração do Garrano e sua interação com a envolvente socioambiental}

O Garrano é um cavalo pequeno e robusto e constitui uma das três raças de equinos autóctones de Portugal, juntamente com as raças Lusitana e Sorraia. A sua população distribui-se pelas terras altas do Norte de Portugal, sendo o Minho, a área do Parque Nacional da Peneda-Gerês (PNPG), a Área de Paisagem Protegida do Corno do Bico e a Serra da Cabreira o seu solar (Leite, 2012; Câmara Municipal de Viana do Castelo, 2019).

As suas extremidades curtas e a pelagem grossa têm permitido uma boa adaptação às regiões montanhosas, frias e húmidas do Norte Peninsular. O Garrano foi, assim, sendo selecionado pelo meio natural, permitindo-lhe aprimorar uma excecional adaptação e integração nos ecossistemas de montanha, condicionando a sua aptidão e utilização, mantendo as suas características desde os tempos mais remotos até hoje (Leite, 2012). De acordo com Leite (2012), é um cavalo para sela, tiro ligeiro e carga a dorso, com especial aptidão para caminhos de montanha e pequenos trabalhos agrícolas.

De facto, a adaptação milenar do Garrano ao habitat de montanha conferiu-lhe uma especial aptidão enquanto animal de transporte de pessoas e mercadorias em áreas de 
morfologia acidentada, com relevos íngremes, tendo sido o meio de locomoção ideal nas veredas do alto Portugal (Leitão, 2009).

Para além de animal de transporte, o Garrano era também utilizado no desempenho de tarefas agrícolas. Todavia, a diminuição da sua utilização nestes trabalhos, devido à introdução da mecanização agrícola, e o contributo de outros fatores extrínsecos, como os predadores naturais e a exploração de raças exóticas, mas também de fatores intrínsecos, como a estocasticidade demográfica e genética, estiveram na origem da regressão numérica destes animais (Quadro 1), verificada essencialmente na última metade do século passado (Leitão, 2009; Leite 2012). Todos estes fatores foram confirmados na fase de desenvolvimento das entrevistas.

Quadro 1. Evolução do efetivo da raça Garrana

\begin{tabular}{cccccc} 
& $1870^{a}$ & $1940^{a}$ & $1999^{a}$ & $2010^{a}$ & $2^{a}$ \\
Efetivo da raça & 16.898 & 14.798 & 2.041 & 1.526 & 2.202 \\
\hline
\end{tabular}

Fontes: (a) Lima (1873); Direcção Geral dos Serviços Pecuários (1940) e ACERG (1999 e 2011) como citados em Leite (2012); e (b) Leite (2019).

O efetivo Garrano tem vindo a reduzir-se drasticamente, passando de cerca de 14.798 equinos, em 1940, para cerca de 1500 animais, em 2010 (Quadro 1), tendo por isso sido classificado como "em via de extinção". Porém, na última década, o efetivo apresentou uma ligeira recuperação, contando atualmente, de acordo com os animais inscritos no Registo Zootécnico (Leite, 2019), com 2.006 fêmeas e 196 machos, explorados por 447 criadores.

Com exceção de alguns animais estabulados para o ainda apoio à lavoura tradicional ou com o objetivo de aumentar o número de exemplares da raça, a maioria dos criadores mantém os Garranos nas serras onde atualmente vivem no estado semisselvagem, sendo criados em regime livre (Leite, 2012). De acordo com Leite (2012), a maioria vive em grupos de dimensão variável (10 a 50 indivíduos), sendo a média 20 éguas. A informação recolhida via inquérito permite destacar a existência de três perfis de criadores, que se diferenciam não só pelo número de animais explorados (inferior a 2; entre 2 e 20; e mais do que 20), mas também pelo objetivo com que a exploração é realizada, pelo regime de criação adotado e pelo usufruto (ou não) de apoios monetários à atividade, que no caso de serem auferidos, o seu valor varia entre os 200 a 600 Euros/animal (Quadro 2).

Quadro 2. Perfil de criadores da raça Garrana

\begin{tabular}{|c|c|c|c|}
\hline Número de animais & Objetivo & Regime de criação & $\begin{array}{c}\text { Apoios monetários } \\
\text { à atividade }\end{array}$ \\
\hline Garranos $\leq 2$ & $\begin{array}{l}\text { Garrano visto como } \\
\text { um animal de } \\
\text { companhia. }\end{array}$ & $\begin{array}{l}\text { Criadores criam os } \\
\text { animais na serra, em } \\
\text { regime livre. }\end{array}$ & $\begin{array}{l}\text { Criadores não } \\
\text { usufruem. }\end{array}$ \\
\hline $2<$ Garranos $\leq 20$ & $\begin{array}{l}\text { Aumentar o número } \\
\text { de animais e obter } \\
\text { algum rendimento } \\
\text { através da venda e } \\
\text { aquisição de animais. }\end{array}$ & $\begin{array}{l}\text { Animais inscritos no livro } \\
\text { genealógico e sujeitos a } \\
\text { algumas operações de } \\
\text { maneio do criador. }\end{array}$ & Criadores usufruem. \\
\hline Garranos > 20 & $\begin{array}{l}\text { Rentabilizar a } \\
\text { atividade. }\end{array}$ & $\begin{array}{l}\text { Animais inscritos no livro } \\
\text { genealógico e controlados } \\
\text { através das operações de } \\
\text { maneio do criador. }\end{array}$ & Criadores usufruem. \\
\hline
\end{tabular}

Fontes: Informação recolhida via inquérito.

Para além da paixão que a generalidade dos criadores manifesta por estes animais, o facto de o Garrano ser percebido como um animal de companhia vai ao encontro de Brubaker e Udell (2016), que enfatizam a grande capacidade de interação entre o homem e o cavalo, com reflexos importantes nas práticas de equitação e terapêuticas, e noutros contextos de trabalho. 
O maneio da maior parte do efetivo da raça Garrana é em regime de pastoreio livre (semisselvagem), em que os animais apascentam todo o ano nos baldios e serras na sua zona de dispersão (Leite, 2012). Esta informação foi confirmada pelos entrevistados, sendo apontada como prática comum a recolha dos animais à noite, no Inverno, havendo, no entanto, algumas exceções.

Em função da disponibilidade de água e alimento, da existência de crias e da ocorrência de predadores, os grupos de animais podem deslocar-se até $40 \mathrm{~km}$ por dia. Leite (2012) indica a predação feita pelo lobo como um dos problemas mais graves deste regime de exploração semisselvagem, que dizima anualmente mais de um terço dos efetivos nascidos. Todavia, apesar de os entrevistados identificarem o mesmo problema, atualmente, os números associados a esta predação transformam-no numa realidade mais preocupante, onde mais de $90 \%$ do efetivo que nasce é dizimado pelo lobo.

Os Invernos rigorosos e as secas prolongadas dos últimos anos são outro fator de perda de produtividade, resumida a uma parição anual, que aliada ao aumento da temperatura fez multiplicar o número de ectoparasitas provocando a morte a animais mais debilitados (Leite, 2012). Porém, o Garrano é um cavalo rústico e de montanha, bastante resistente em todos os sentidos.

Na atualidade, o cavalo Garrano continua ainda a ser utilizado com um cavalo de sela (Leite, 2012; Câmara Municipal de Viana do Castelo, 2019). Todavia, enraizado na tradição étnica, costumes e património cultural das gentes do Norte, é essencialmente explorado no sentido de satisfazer necessidades lúdicas do utilizador moderno, participando no turismo rural e equestre, nomeadamente nas corridas de Garranos (Leitão, 2009).

Leite (2012) considera que os produtos obtidos anualmente têm destinos diferentes conforme a sua genealogia, qualidade e maior ou menor procura do mercado. A esta listagem, os entrevistados acrescentaram ainda a influência do prestador de serviços (se criador ou empresário).

As fêmeas e machos que se destacam pelas suas excecionais qualidades destinam-se à recria e apuramento genético da raça, sendo utilizados para substituição ou aumento de efetivo. Os restantes animais são vendidos ao desmame (por volta dos seis meses), principalmente para outras explorações e, de forma residual, destinados à produção de carne. Tal informação corresponde ao referido por Leite (2012).

Os entrevistados indicaram que o tamanho mais reduzido destes cavalos proporciona características de conforto, o que tem permitido um grande sucesso na sua utilização em práticas desportivas (atrelagem, corridas, horseball, equitação, entre outras) e de turismo equestre (turismo de montanha e agroturismo, ecoturismo), o que vai ao encontro do exposto nos documentos literários sobre o Garrano (Brito, 2011; Leite, 2012). Sendo um animal dócil, é também utilizado em hipoterapia e como cavalo de iniciação à equitação, principalmente com crianças. O único problema referido pelos entrevistados relaciona-se com o peso das pessoas a transportar por estes animais, limitado a $70 \mathrm{~kg}$, o que inviabiliza o seu uso por turistas com peso superior. Esta situação sucede com alguma frequência, nomeadamente com turistas estrangeiros (ingleses) que, na sua generalidade, são mais pesados e com maior porte.

O Garrano é usado ainda para limpeza dos terrenos e para reduzir a biomassa combustível, sendo caracterizados por alguns dos criadores entrevistados como "piores que um bulldozer". Porém, trata-se de uma valência que não é reconhecida por todos os entrevistados, nem remunerada ou requisitada. É mais entendida como uma externalidade positiva que deriva do facto destes animais pastorearem, sobretudo, terrenos baldios.

No decorrer das entrevistas, foi evidenciado que, em comparação com outros animais, os Garranos são menos seletivos e consomem bastante vegetação. Um criador, que também possui cabras, afirmou que "a cabra come tudo, mas o Garrano come mais!".

Para as diferentes aptidões e usos, o Garrano mostrou-se como um animal em equilíbrio com a natureza e com as condições socioeconómicas existentes, devido a: (a) tratar-se de uma raça bem-adaptada às modalidades ecoturísticas; (b) apresentar elevada rusticidade e resistência; (c) representar uma raça autóctone que importa preservar, promover e valorizar; e (d) ao menor custo de produção quando comparado com um Lusitano - "os Garranos comem menos que um cavalo. Em termos de forragem igual, mas em termos de ração vai para metade". 


\subsection{Custos e benefícios económicos com o Garrano}

Aparentemente, através da informação via inquérito, o criador de Garranos não usufrui de elevada rentabilidade com a sua exploração, quer a base de negócio seja a criação ou os serviços que prestam quer pelos subsídios que podem auferir.

De acordo com o sistema de exploração utilizado, podem identificar-se três situações genéricas de custos e benefícios (Quadro 3).

No topo de menor custos está o regime em que os animais são criados em liberdade "no monte". Neste caso, os custos com a alimentação suplementar e com a estabulação é nula ou muito reduzida. Como fonte de rendimento, os criadores beneficiam dos subsídios atribuídos aos animais, essencialmente via Medidas Agroambientais (Portugal, 2015), e das vendas dos poldros. Porém, a taxa de mortalidade dos jovens animais é muito elevada, essencialmente devido à predação do lobo e às condições climatéricas, podendo originar perdas de efetivo até um terço. Neste caso, quer os custos quer os rendimentos económicos apresentam-se muito reduzidos. Porém, as externalidades económicas obtidas devido à ação do pastoreio, com efeitos na gestão da biomassa combustível, risco de incêndios, conservação dos ecossistemas e manutenção da biodiversidade são muito significativas.

Nos outros sistemas identificados no Quadro 3, os animais pastoreiam durante o dia e pernoitam no estábulo, apresentando como diferença a utilidade do Garrano. Nestes casos, os custos alimentares e com a mão de obra são, obviamente, mais significativos. Pela estimativa apresentada por alguns dos criadores entrevistados, verifica-se o consumo de um fardo de feno diário por animal adulto, originando um custo de cerca de dois a três Euros diários, o que pode representar uma despesa aproximada de 270 Euros anuais por animal. Poderá ser-Ihes dada ainda forragem e ração. Quando estabulado todo o ano, a informação recolhida via inquérito aponta para uma despesa mensal, por Garrano, a rondar os 65 a 90 Euros, mas que varia inversamente com a área disponível para pastoreio.

Nestes últimos casos, existem ainda custos com a mão de obra, que se elevam quando a criação é feita com o ensino do cavalo, sendo este custo refletido posteriormente no preço de venda do animal.

Quadro 3. Custos e benefícios dos sistemas adotados para a exploração do Garrano

\begin{tabular}{|c|c|c|c|}
\hline Sistema de exploração & Custos económicos & $\begin{array}{l}\text { Rendimentos } \\
\text { económicos }\end{array}$ & $\begin{array}{l}\text { Efeitos diretos no } \\
\text { ambiente }\end{array}$ \\
\hline $\begin{array}{l}\text { Pastoreio permanente, } \\
\text { sem estabulação }\end{array}$ & Nulos ou reduzidos & $\begin{array}{l}\text { Reduzidos: subsídios; e } \\
\text { venda do poldro (com } \\
\text { elevada taxa de } \\
\text { mortalidade) }\end{array}$ & $\begin{array}{l}\text { Significativos: gestão da } \\
\text { biomassa com efeitos na } \\
\text { biodiversidade e na } \\
\text { preservação de } \\
\text { ecossistemas }\end{array}$ \\
\hline $\begin{array}{c}\text { Estabulação e pastoreio } \\
\text { temporário: Garrano } \\
\text { não prestador de } \\
\text { serviços }\end{array}$ & $\begin{array}{l}\text { Significativos: } \\
\text { alimentação } \\
\text { suplementar; } \\
\text { estabulação; mão de } \\
\text { obra; veterinário }\end{array}$ & $\begin{array}{c}\text { Reduzidos: subsídios; } \\
\text { venda do poldro; venda } \\
\text { de estrume }\end{array}$ & \\
\hline $\begin{array}{c}\text { Estabulação e pastoreio } \\
\text { temporário: Garrano } \\
\text { prestador de serviços }\end{array}$ & $\begin{array}{l}\text { Significativos: } \\
\text { alimentação } \\
\text { suplementar; } \\
\text { estabulação; mão de } \\
\text { obra; veterinário; } \\
\text { transporte; } \\
\text { campeonatos; e outros }\end{array}$ & $\begin{array}{l}\text { Significativos: subsídios; } \\
\text { venda do poldro, com } \\
\text { valor superior; venda de } \\
\text { estrume; prestação de } \\
\text { serviços através de } \\
\text { atividades equestres, } \\
\text { turísticas e de saúde; } \\
\text { prémios }\end{array}$ & $\begin{array}{c}\text { Dependente do tempo e } \\
\text { percurso do pastoreio }\end{array}$ \\
\hline
\end{tabular}

Fontes: Informação recolhida via inquérito.

Outros custos identificados no processo de entrevista foram relativos aos serviços veterinários (cerca de 70 Euros a consulta), medicamentos e tratamentos, desparasitantes e registo no livro genealógico (entre 55 e 60 Euros). 
Foram identificados custos avultados sempre que é necessário transporte dos cavalos, nomeadamente com os camiões ou veículos próprios, para além dos custos associados à própria viagem (portagens de classe 4). A participação em campeonatos regionais de atrelagem cifra-se em valores compreendidos entre os 3000 e os 4000 Euros.

No que concerne aos rendimentos obtidos com os Garranos, eles são variados. Os cavalos (póneis) têm preços diferenciados, consoante a idade, o sexo e a preparação que têm para determinado fim ou disciplina (praticando-se os valores referidos anteriormente). Para uns inquiridos, o objetivo passa por criá-los ou adquiri-los, treiná-los e depois vendê-los com essa preparação. Para outros, a venda pode acontecer a qualquer altura do desenvolvimento do cavalo. No geral, os principais propósitos da exploração do Garrano pelo seu criador, identificados via inquérito, foram os seguintes, variando o preço de venda em função das caraterísticas morfológicas apresentadas pelos animais:

- venda de poldros ao desmame (abate ou revenda);

- $\quad$ venda de poldros para serem treinados e criados por outros criadores;

- $\quad$ venda de animais jovens/adultos para serem treinados;

- $\quad$ participação em modalidades equestres desportivas;

- prestação de serviços ecoturísticos.

Através das mesmas fontes de informação, o poldro ao desmame é vendido na região pelo criador por apenas 150 a 300 Euros, enquanto que, se os póneis forem selecionados (entenda-se "bonitos" e de linhagem reconhecidamente boa), o preço é superior a 1000 Euros. No geral, os criadores consideraram haver falta de promoção e valorização destes animais, para que um preço de venda mais elevado fosse atingido.

Entre os criadores também é usual a transação de animais adultos, custando as fêmeas adultas entre 300 Euros e, se for "boa", 500 a 600 Euros. O macho é mais caro, e é vendido pelo valor mínimo de 1000 Euros, mas foi também referida a sua transação por 2000 Euros para a sua venda, não sendo, no entanto, um valor que permita um lucro comparável com o de outras raças equinas, "Com o Garrano, é um bocado por carolice".

Em termos de ajudas monetárias, os entrevistados referiram diferentes valores usufruídos pelos criadores, desde 200 a 600 Euros por animal, e que se torna um contributo importante para a manutenção da sua exploração. Porém, enquanto uns referem que se não fosse o subsídio, não havia quem os criasse, outros dizem que, mesmo em prejuízo, há pessoas que gostam de ter um Garrano "como quem gosta de ter um cão ou um gato".

Quanto aos serviços prestados pelo Garrano, desde batismos a passeios a cavalo e em charrete, os preços variam entre 8 e 120 Euros.

A venda destes animais para carne não é muito usual, mas quando praticada surge da venda direta dos poldros ao desmame, por 50 a 75 Euros, pelo criador a negociantes, geralmente talhantes, ou a comerciantes que fazem posteriormente a sua revenda, e é mais direcionada para o mercado espanhol. Alguns produtores referiram terem vendido poldros nestas condições, mas por valores mais elevados, na ordem dos 250-300 Euros.

Embora o estrume de Garrano não seja muito apreciado, a sua venda em tratores de 2 toneladas rende 100 Euros.

Os concursos de Garranos também ajudam a tirar algum rendimento, através de prémios que recebem.

\subsection{Análise sintética da exploração do Garrano}

O diagnóstico obtido através da análise à informação recolhida via inquérito, complementada com a breve recolha de literatura sobre o tema, está sintetizado no formato de análise SWOT no Quadro 4, e estruturado por dimensão ambiental, económica e social.

De forma esquemática e sintética, o desequilíbrio entre os pontos fortes e oportunidades relativamente às debilidades e ameaças apresentadas permitem evidenciar o potencial positivo verificado com a exploração do Garrano. É, no entanto, implícito que este potencial toma forma se enquadrado numa estratégia concertada de valorização dos produtos (bens ou serviços) obtidos, que se tenta enunciar no ponto seguinte. 
Quadro 4. Diagnóstico da sustentabilidade da raça Garrana

\begin{tabular}{|c|c|c|c|c|}
\hline & Forças & Debilidades & Oportunidades & Ameaças \\
\hline \multirow{6}{*}{ 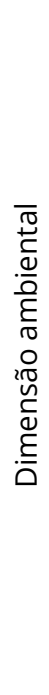 } & - Património genético & - Regressão do efetivo & $\begin{array}{l}\text { - Gestão da biomassa mais } \\
\text { efetiva do que outras espécies }\end{array}$ & $\begin{array}{l}\text { - Raça em via de } \\
\text { extinção }\end{array}$ \\
\hline & $\begin{array}{l}\text { - Características de } \\
\text { rusticidade e de } \\
\text { adaptação à montanha }\end{array}$ & $\begin{array}{l}\text { - Cruzamento dos animais } \\
\text { com outras raças }\end{array}$ & - Redução de fogos florestais & - Predadores (lobo) \\
\hline & $\begin{array}{l}\text { - Consome e aproveita } \\
\text { recursos endógenos não } \\
\text { valorizados }\end{array}$ & $\begin{array}{l}\text { - Baixa taxa de sobrevivência } \\
\text { de jovens }\end{array}$ & $\begin{array}{l}\text { - Manutenção da paisagem e } \\
\text { ecossistemas }\end{array}$ & \\
\hline & $\begin{array}{l}\text { - Controlo do mato } \\
\text { através do pastoreio } \\
\text { animal }\end{array}$ & & $\begin{array}{l}\text { - Conservação da } \\
\text { biodiversidade }\end{array}$ & \\
\hline & $\begin{array}{l}\text { - Baixo encabeçamento } \\
\text { animal }\end{array}$ & & $\begin{array}{l}\text { - Manutenção e valorização de } \\
\text { espaços agroflorestais } \\
\text { abandonadas }\end{array}$ & \\
\hline & $\begin{array}{l}\text { - Não dependente de } \\
\text { recursos externos }\end{array}$ & & $\begin{array}{l}\text { - Extensas áreas de matos em } \\
\text { terrenos comunitários }\end{array}$ & \\
\hline \multirow{4}{*}{ 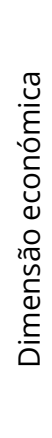 } & $\begin{array}{l}\text { - Diversidade de } \\
\text { produtos/serviços }\end{array}$ & $\begin{array}{l}\text { - Baixo rendimento } \\
\text { económico }\end{array}$ & $\begin{array}{l}\text { - Integração e complemento do } \\
\text { sistema produtivo agroflorestal }\end{array}$ & $\begin{array}{l}\text { - Substituição por } \\
\text { raças mais produtivas }\end{array}$ \\
\hline & $\begin{array}{l}\text { - Baixos custos de } \\
\text { produção }\end{array}$ & $\begin{array}{l}\text { - Taxa de mortalidade } \\
\text { elevada dos animais jovens }\end{array}$ & $\begin{array}{l}\text { - Reconhecimento das mais- } \\
\text { valias económicas que } \\
\text { proporciona }\end{array}$ & - Subsídios à atividade \\
\hline & - Subsídios à atividade & - Associativismo débil & $\begin{array}{l}\text { - Criação de valor (turismo, } \\
\text { desporto, saúde, agricultura, } \\
\text { ambiente) }\end{array}$ & \\
\hline & & & $\begin{array}{l}\text { - Raça apoiada por medidas } \\
\text { comunitárias }\end{array}$ & \\
\hline \multirow{6}{*}{ 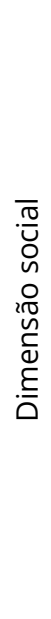 } & $\begin{array}{l}\text { • Enraizado na tradição } \\
\text { étnica, costumes e } \\
\text { património cultural }\end{array}$ & $\begin{array}{l}\text { - Regressão na participação } \\
\text { de atividades agrícolas }\end{array}$ & $\begin{array}{l}\text { - Reconhecimento da } \\
\text { importância da raça animal }\end{array}$ & $\begin{array}{l}\text { - Diminuição da } \\
\text { população rural }\end{array}$ \\
\hline & • Regime de exploração & $\begin{array}{l}\text { - Condições pobres de bem- } \\
\text { estar animal }\end{array}$ & $\begin{array}{l}\text { - Diferentes iniciativas e } \\
\text { projetos de apoio ao Garrano }\end{array}$ & $\begin{array}{l}\text { - Envelhecimento dos } \\
\text { criadores }\end{array}$ \\
\hline & $\begin{array}{l}\text { - Paixão dos criadores } \\
\text { pelos Garranos }\end{array}$ & & $\begin{array}{l}\text { - Existência de uma Associação } \\
\text { para desenvolvimento e } \\
\text { proteção da raça }\end{array}$ & \\
\hline & & & - Criação potencial de emprego & \\
\hline & & & $\begin{array}{l}\text { - Participação em atividades de } \\
\text { turismo, desporto, saúde, } \\
\text { paisagem }\end{array}$ & \\
\hline & & & $\begin{array}{l}\text { - Melhoria das condições de } \\
\text { vida das populações }\end{array}$ & \\
\hline
\end{tabular}

\subsection{Atividades para a valorização do Garrano}

$\mathrm{Na}$ literatura consultada e através das entrevistas realizadas, verificam-se algumas iniciativas e estratégias desenvolvidas que visam a defesa e proteção desta raça, em função do protagonismo do Garrano nos contextos sintetizados no Quadro 4. No Quadro 5 listam-se algumas dessas iniciativas, que deverão ter contribuído para o acréscimo de $44 \%$ do efetivo, entre 2010 e 2019 (Quadro 1), sendo, no entanto, o número de Garranos ainda insuficiente para que a raça perca a classificação de "em risco de extinção". 
Quadro 5. Iniciativas desenvolvidas para a proteção e valorização do Garrano

\begin{tabular}{|c|c|c|}
\hline Iniciativa & Objetivo & Fonte \\
\hline $\begin{array}{l}\text { Criação da Associação de } \\
\text { Criadores de Equinos de } \\
\text { Raça Garrana (ACERG) }\end{array}$ & $\begin{array}{l}\text { Entidade fundada em 1990, responsável pelo registo zootécnico e } \\
\text { livro genealógico da raça. }\end{array}$ & Leite (2012) \\
\hline $\begin{array}{l}\text { Candidatura do Garrano } \\
\text { a Património Nacional }\end{array}$ & $\begin{array}{l}\text { Lançada em 2009, no decurso da Feira do Cavalo, em Ponte de } \\
\text { Lima. Visa contribuir para a manutenção de um recurso biológico } \\
\text { insubstituível integrando, num conceito holístico, perspetivas } \\
\text { produtivas, genéticas, ambientais, sociais e culturais, evitando a } \\
\text { tendência regressiva de uma raça autóctone e reforçando o } \\
\text { orgulho e a identidade de um povo. }\end{array}$ & Brito (2011) \\
\hline $\begin{array}{l}\text { Prémio Internacional de } \\
\text { Investigação do Garrano - } \\
\text { Fundação Caixa Noroeste }\end{array}$ & $\begin{array}{l}\text { Prémio bienal a Projetos e/ou Estudos Científicos relativos à Raça } \\
\text { Garrana, apoiado pela Fundação Caixa Noroeste }\end{array}$ & Brito (2011) \\
\hline $\begin{array}{l}\text { I Congresso Internacional } \\
\text { do Garrano }\end{array}$ & $\begin{array}{l}\text { Realizado em 2011, com o objetivo de demonstrar a importância e } \\
\text { a necessidade em se definirem políticas de salvaguarda duma das } \\
\text { três raças equinas autóctones existentes em Portugal. }\end{array}$ & Alves (2012) \\
\hline $\begin{array}{l}\text { Medida Manutenção de } \\
\text { Raças Autóctones em } \\
\text { risco }\end{array}$ & $\begin{array}{l}\text { Apoio monetário que visa contribuir para a melhoria da viabilidade } \\
\text { das explorações em zonas rurais com poucas alternativas, para a } \\
\text { melhoria do ambiente e da paisagem rural, tendo em conta os } \\
\text { sistemas extensivos a que estão associadas. Estas explorações } \\
\text { pecuárias são exemplo da multifuncionalidade na atividade } \\
\text { agrícola e constituem um contributo indispensável para os } \\
\text { sistemas de produção em equilíbrio com o ambiente, pelo que } \\
\text { importa promover a conservação in situ destes recursos genéticos } \\
\text { animais autóctones, designadamente os que estão em risco de } \\
\text { extinção. }\end{array}$ & MAR (2015) \\
\hline $\begin{array}{l}\text { Projeto Percursos do } \\
\text { Homem e do Garrano }\end{array}$ & $\begin{array}{l}\text { Visa aproximar o Garrano das populações e visitantes, conferindo- } \\
\text { Ihe um novo protagonismo na fruição turística e de lazer dos } \\
\text { nossos espaços naturais de excelência e promovendo a divulgação } \\
\text { das características, habitat e potencialidades da raça. }\end{array}$ & $\begin{array}{l}\text { Câmara } \\
\text { Municipal de } \\
\text { Viana do } \\
\text { Castelo (2019) }\end{array}$ \\
\hline
\end{tabular}

Neste sentido, devido à importância do Garrano e seu potencial contributo ao nível ambiental, económico e social, apresentam-se de seguida os desafios e oportunidades, recolhidas através da fase de inquirição e enquadradas nas análises desenvolvidas nos pontos anteriores. Estes elementos visam constituir-se como integradores de uma estratégia de valorização do Garrano, tendo por base a reinvenção das funções do animal nos modos de vida, aspirações e necessidades das novas gerações.

1. Integrar o Garrano nos sistemas de exploração agroflorestais já existentes, para que haja complementaridade do ponto de vista económico e ambiental, sem grandes diferenças ao nível das práticas de maneio utilizadas pelo criador;

2. Rentabilizar e fomentar o empreendedorismo na oferta de serviços do Garrano através do aproveitamento do seu potencial em modalidades equestres e outras atividades de desporto, de saúde (hipoterapia), de turismo e também ambientais;

3. Integrar na cadeia de valor os diversos produtos (bens e serviços) já existentes e os que podem ser desenvolvidos com o sistema produtivo do Garrano, acompanhado de esquemas que permitam reconhecer o valor associado ao produto (caso de animais vivos; caso da carne para consumo; caso dos serviços prestados);

4. Desenvolver estratégias de marketing concertadas e associadas ao território, envolvendo os vários atores interessados na cadeia de valor e no desenvolvimento e proteção da raça;

5. Desenvolver estudos e projetos, de âmbito científico, que permitam reconhecer o valor, qualidades e aptidões do Garrano e permitir melhor adaptação das aptidões de cada espécie e raça ao contexto da sua utilização;

6. Promover iniciativas de sensibilização e divulgação da raça junto da população em geral. 


\section{CONCLUSÕES}

De uma forma geral, a utilização do Garrano foi-se tornando residual ao longo dos tempos, o que tem desvalorizado a atividade de exploração dos animais e desmotivado os seus criadores e empresários. Problemas como o lobo, o despovoamento das zonas rurais e a substituição das atividades existentes por outras mais rentáveis têm acentuado a situação atual do cavalo Garrano. Surge, assim, a necessidade de refletir seriamente sobre as capacidades e oportunidades que a exploração destes animais apresenta, no sentido de identificar os seus potenciais benefícios. Será, porventura, necessário um debate mais participado entre diversas entidades, públicas e privadas, para valorizar a raça e tirar maior proveito das suas aptidões.

São já exemplos os seus benefícios para a sustentabilidade ambiental, com efeitos positivos na defesa da floresta contra incêndios e na manutenção dos ecossistemas e da biodiversidade; as suas mais-valias económicas através da rentabilização da prestação dos seus serviços; e seus efeitos na melhoria das condições de vida das suas populações.

Após a síntese do diagnóstico efetuado em torno do Garrano e seus serviços, sistema de exploração, custos e benefícios, consideramos que a conceção de uma estratégia de valorização destes animais só poderá ser atingida na medida em que se observe uma intervenção multidisciplinar, integrada e sustentável nas dimensões coletiva, históricocultural, económica, ambiental e social.

A dimensão coletiva ocupará um lugar central. Consideramos que se trata de um aspeto que deve ser reformulado em termos de atuação, de modo a ajustar-se às expetativas dos criadores e empresários e outras entidades públicas e privadas. Trata-se, portanto, de desenvolver uma metodologia bottom-up que vá ao encontro dos interesses e expectativas dos envolvidos e que seja capaz de criar um dinamismo coletivo favorável e sustentável para todos, assim como para a preservação, promoção e valorização dos Garranos.

Tratando-se de um património genético vivo com significado histórico-cultural associado que importa proteger e valorizar, entende-se que a dimensão histórica/cultural também deverá estar presente apostando-se em ações de sensibilização, destacando as suas raízes históricas, a sua importância ecológica e ambiental e as potencialidades inerentes aos serviços que podem ser desenvolvidos numa perspetiva mais económica e de empreendedorismo. Uma ideia paralela seria a de estabelecer uma Rota do Garrano, que ajudasse a valorizar e a promover a raça e contribuísse ao mesmo tempo para a sua proteção e preservação. Esta iniciativa estaria, indubitavelmente, relacionada com o restante património histórico, cultural, gastronómico e paisagístico da região do solar do Garrano.

Numa dimensão mais económica, importa considerar as iniciativas de empreendedorismo que podem ser desenvolvidas com o Garrano, necessárias à criação de riqueza e à manutenção dos atores que dela dependem. Desde os serviços agroambientais, como a gestão de biomassa combustível direcionada para espaços devidamente identificados, passando pelo turismo de natureza, com passeios equestres, até à participação em diversas modalidades equestres, como a atrelagem e a iniciação à equitação, ou o uso desta raça para fins terapêuticos, existe um leque de potenciais usos a dar ao Garrano. Este tipo de serviço mais específico, designadamente o pastoreio dos animais nos espaços florestais, é, atualmente, considerado uma externalidade positiva. Quer isto dizer que se trata de uma consequência positiva que deriva do facto de os animais pastorearem determinadas áreas, não sendo, porém, contabilizado o importante serviço que prestam na manutenção da paisagem, na redução do risco de incêndio e na preservação de habitats florísticos e faunísticos num determinado território.

Está, assim, também inerente a dimensão ambiental que passa por garantir que o Garrano é parte da solução na preservação da paisagem e de ecossistemas importantes, que garantem o equilíbrio ecológico de um determinado território. Na verdade, as espécies ameaçadas de extinção representam um desequilíbrio no ecossistema que tem repercussões em toda a biosfera, sendo de extrema importância desenvolver esforços que permitam o equilíbrio dos seus números. Esta realidade tem exemplo na iniciativa desenvolvida pela Associação Transumância e Natureza que, na Reserva da Faia Brava (Vale do Côa), vem desenvolvendo há cerca de 15 anos a esta parte um programa de introdução desta espécie 
nos 1000 ha de território que estão sob sua gestão (informação obtida por inquérito). Também as medidas agroambientais, nomeadamente os programas de preservação de raças autóctones, que apoiam os criadores europeus através da Política Agrícola Comum, são prova do interesse em restabelecer populações equilibradas destes animais. Além do património genético valioso que a própria raça encerra, a gestão ambiental promovida pelo Garrano pode ser considerada a vários níveis. Salienta-se o seu papel na construção e manutenção da paisagem, na defesa dos sistemas agro-silvo-pastoris e no equilíbrio dos ecossistemas que Ihe estão associados, através da utilização eficiente dos recursos disponíveis, tais como as áreas de matos, muitos deles sem qualquer outro tipo de aproveitamento. A redução da biomassa arbustiva e a prevenção de incêndios que poderão proporcionar permite-lhes a conservação da biodiversidade, da preservação do ar, dos solos e dos sistemas aquíferos, um papel que não pode ser substituído.

Finalmente, e porque o Homem é parte integrante do território, tudo o que foi referido anteriormente pode justificar e fundamentar a dimensão social da estratégia, na medida em que se observará um forte contributo das diferentes iniciativas para a dinamização do tecido económico local e regional, o incentivo ao turismo de natureza destas regiões (onde o potencial é enorme) e à fixação cada vez maior da população em zonas demograficamente desfavorecidas.

\section{REFERÊNCIAS BIBLIOGRÁFICAS}

Altieri, M. A. (1994). Bases Agroecologicas para una Produccion Agrícola Sustentable. Agricultura Técnica (Chillán), 54(4), 371-386.

Alves, J. (2012, setembro 23-25). Nota de Editor. In N. Brito \& J. Alves (Coord.), I Congresso Internacional do Garrano. Candidatura a Património Nacional, Livro de Atas. Arcos de Valdevez: ATAHCA Associação de Desenvolvimento das Terras Altas do Homem, Cávado e Ave. (pp. 7-9). Recuperado em 06 de setembro de 2019, de http://garrano.ipvc.pt/files/livro_atas.pdf

Brito, N. (2011). Intenção de candidatura do Garrano a Património Nacional. Viana do Castelo: IPVC. Recuperado em 06 de setembro de 2019, de http://garrano.ipvc.pt/

Brubaker, L., \& Udell, M. A. R. (2016). Cognition and learning in horses (Equus caballus): What we know and why we should ask more. Behavioural Processes, 126, 121-131. http://dx.doi.org/10.1016/j.beproc.2016.03.017

Câmara Municipal de Viana do Castelo - CMVC. (2019). Garrano. Recuperado em 15 de julho de 2019, de http://www.garranos.pt/pt/conhecer/territorio

Comissão das Comunidades Europeias - CCE. (2001). Ambiente 2010: o Nosso Futuro, a Nossa Escolha. Sexto Programa de Acção em Matéria de Ambiente. Comunicação da Comissão ao Conselho, ao Parlamento Europeu, ao Comité Económico e Social e ao Comité das Regiões. COM (2001) 31 final. Bruxelas: CCE. $89 \mathrm{p}$.

Esquivel, C. E. G. (1998). Evaluation of sustainability in dairy cattle production systems (Doctoral dissertation). University of London, London.

Leitão, N. (2009). O Garrano, o pequeno cavalo das serras do Norte de Portugal. Recuperado em 15 de julho de 2019, de http://naturlink.pt/article.aspx?menuid=23\&cid=4672\&bl=1\&viewall=true

Leite, J. (2012). A Raça Equina Garrana. In N. Brito \& J. Alves (coord). I Congresso Internacional do Garrano. Candidatura a Património Nacional, Livro de Atas. Arcos de Valdevez: ATAHCA - Associação de Desenvolvimento das Terras Altas do Homem, Cávado e Ave. (pp. 30-49). Recuperado em 15 de julho de 2019, de http://garrano.ipvc.pt/files/livro_atas.pdf.

Leite, J. (2019). Equinos - Raça Garrano. Vale de Santarém, Portugal: SPREGA - Sociedade Portuguesa de Recursos Genéticos Animais. Recuperado em 06 de setembro de 2019, de http://www.sprega.com.pt/conteudo.php?idesp=equinos\&idraca=Garrano

Marta-Costa, A. A. (2010a). Agricultura Sustentável I: Conceitos. Revista de Ciências Agrárias (Belém), 33(2), 61-74.

Marta-Costa, A. A. (2010b). Sustainability study for the rearing of bovine livestock in mountainous zones. New Medit, IX(1), 4-12.

Marta-Costa, A., Torres-Manso, F., \& Tibério, L. (2012). Sustainability diagnosis of an agroforestry system. Regional Science Inquiry Journal, 4(2), 111-124. 
Portugal. Ministério da Agricultura e do Mar (2015, fevereiro 27). Portaria $\mathrm{n}^{\circ} .55 .1^{\text {a }}$ série, n. ${ }^{\circ} 41,27$ de fevereiro de 2015. Diário da República, p. 1217-1222.

Portugal. Ministério do Ambiente, do Ordenamento do Território e do Desenvolvimento Regional (2006). Programa Nacional da Política de Ordenamento do Território. Relatório. Lisboa: MAOTDR. Recuperado em 06 de setembro de 2019, de http://pnpot.dgterritorio.gov.pt/sites/default/files/PNPOT_Relatorio.pdf

Parlamento Europeu e do Conselho (2018, junho 14). Regulamento (UE) 2018/848 de 30 de maio de 2018 relativo à produção biológica e à rotulagem dos produtos biológicos e que revoga o Regulamento (CE) n.o 834/2007 do Conselho. Jornal Oficial da União Europeia. L 150.

Reis, P., Rolo, J., Coelho, I., \& Belo, C. C. (2014). Sistemas agroflorestais em Portugal continental: Parte I: economia e distribuição geográfica. Revista de Ciências Agrárias, 37(2), 113-121.

Silva, J. (2012). As assimetrias regionais em Portugal: análise da convergência versus divergência ao nível dos municípios (Dissertação de mestrado). Universidade do Minho, Braga. Recuperado em 06 de setembro de 2019, de http://repositorium.sdum.uminho.pt/bitstream/1822/22795/1/Jos\%c3\%a9\%20Manuel\%20Ferreira \%20da\%20Silva.pdf

Silva, E., \& Marta-Costa, A. A. (2013). The needs for building sustainable farming systems: issues and scope. In A. Marta-Costa \& E. Silva (Eds.), Methods and procedures for building sustainable farming systems: Application in the European context (pp. 1-5). Springer Editions.

Soukiazis, E., \& Antunes, M. (2004). A evolução das disparidades regionais em Portugal ao nível das NUTS III: Uma análise empírica com base nos processos de convergência. Estudos Regionais, 6, 6585. Recuperado em 06 de setembro de 2019, de http://www.apdr.pt/siteRPER/numeros/RPER06/ portugues/art04.pdf

Sousa, J., \& Marta-Costa, A. A. (2016). Evolução da Sustentabilidade em explorações bovinas do Norte de Portugal. In A. A. Marta-Costa; M. L. Tibério \& R. Payan (Org.), Raças autóctones no espaço ibérico: Um Recurso Sustentável (pp. 17-24). Vila Real: UTAD.

Viegas, M., \& Antunes, M. (2012). Convergence at local level: An exploratory spatial analysis applied to the portuguese municipalities. Intereconomics, 48(1), 59-66. Recuperado em 06 de setembro de 2019, de http://www.apdr.pt/congresso/2012/pdf/SESSION_C2.pdf

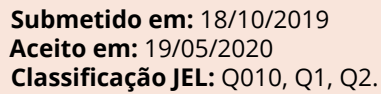

